\title{
Tecnologia e inclusão social: Cooperativa Catamare
}

\author{
Technology and social inclusion: Cooperative Catamare
}

\section{Technologie et inclusion sociale: Catamare Cooperative}

\author{
Tecnología e inclusión social: Catamare Cooperativa
}

\author{
Christian Luiz da Silva* \\ (christianlsilva76@gmail.com) \\ Camille Rossato Bolson* \\ (camille.bolson@gmail.com) \\ Cristina Maria Souto Ferrigoti** \\ (cmferigoti@uol.com.br)
}

Recebido em 07/02/2016; revisado e aprovado em 18/03/2016; aceito em 15/04/ 2016

DOI: http:/ / dx.doi.org/10.20435/1984-042X-2016-v.17-n.3(13)

\begin{abstract}
Resumo: O objetivo deste trabalho foi avaliar as potencialidades e as limitações em tecnologia para inclusão social na cooperativa CATAMARE em Curitiba, Paraná, Brasil. Foi utilizado abordagem qualitativa, sustentada por questionários, entrevistas e observação participante. Como resultado, as evidências sugerem que a organização da cooperativa permitiu acesso a informações sobre legislação, mas observou-se ausência de tecnologia fragilizando a cooperativa em relação à articulação entre pares. Pode-se concluir que a inclusão social dos cooperados melhorou, porém há limites estruturais para o desenvolvimento de ações sustentáveis.
\end{abstract}

Palavras-chave: tecnologia; cooperativismo; inclusão social.

Abstract: The objective of this study was to evaluate the potential and limitations in technology for social inclusion in CATAMARE cooperative in Curitiba, Paraná, Brazil. It used a qualitative approach, supported by questionnaires, interviews and participant observation. As a result the evidence suggests that the organization of the cooperative allowed access to information on legislation, but there was no technology hindering cooperative in relation to the joint between the members. It can be concluded that social inclusion of cooperative members has improved, but there are structural limits to the development of sustainable actions.

Key words: technology; cooperativism; social inclusion.

Résumé: L'objectif de cette étude était d'évaluer le potentiel et les limites de la technologie pour l'inclusion sociale dans CATAMARE coopérative à Curitiba, Paraná, Brésil. Il a utilisé une approche qualitative, soutenue par des questionnaires, des entretiens et l'observation participante. En conséquence, la preuve suggère que l'organisation de la coopérative a permis l'accès à l'information sur la législation, mais il n'y avait pas de technologie entravant la coopération en ce qui concerne l'articulation entre les membres. On peut en conclure que l'inclusion sociale des membres de la coopérative est améliorée, mais il y a des limites structurelles au développement des actions durables. Mots-clés: la technologie; coopératisme; l'inclusion sociale.

Resumen: El objetivo de este estudio fue evaluar el potencial y las limitaciones de la tecnología para la inclusión social en cooperación CATAMARE en Curitiba, Paraná, Brasil. Se utilizó un enfoque cualitativo, con el apoyo de cuestionarios, entrevistas y observación participante. Como resultado, la evidencia sugiere que la organización de la cooperativa permite el acceso a la información sobre la legislación, pero no había ninguna tecnología, lo que dificulta la acción de la cooperativa en relación con la unión entre los miembros. Se puede concluir que la inclusión social de los miembros de la cooperativa ha mejorado, pero hay límites estructurales para el desarrollo de acciones sostenibles.

Palabras clave: tecnología; cooperativismo; inclusión social.

\footnotetext{
* Universidade Tecnológica Federal do Paraná (UTFPR), Curitiba, Paraná, Brasil.

** Centro Universitário Internacional (UNINTER), Curitiba, Paraná, Brasil.
} 


\section{INTRODUÇÃO}

Este artigo enfoca tecnologia social e inclusão na Cooperativa de Catadores de Materiais Recicláveis (CATAMARE) localizada em Curitiba, PR, BR, a partir da sanção da Política Nacional de Resíduos Sólidos (PNRS), como um contributo ao desenvolvimento local por meio de ações sustentáveis.

O objetivo deste trabalho foi analisar as potencialidades e as limitações da cooperativa CATAMARE, em tecnologias sociais após a sanção da PNRS, para o desenvolvimento local por meio de ações sustentáveis, notadamente a inclusão social de catadores de materiais recicláveis. O modelo de gestão trazido pela PNRS, para desenvolvimento local por meio de ações sustentáveis, propõe a inclusão social de catadores de material reciclável no sistema de gerenciamento de resíduos.

A PNRS é um fator importante para a inclusão social, a partir da criação de metas que objetivam contribuir para a eliminação dos aterros sanitários onde são depositados resíduos sólidos gerados pela atividade humana (resíduos domésticos, comerciais, de serviços de saúde e da indústria da construção). Tanto a esfera pública quanto a privada estão envolvidas, tendo sido constituído o Comitê Interministerial para Inclusão Social e Econômica dos Catadores de Materiais Reutilizáveis e Recicláveis (CIISC), coordenado pela Secretaria Geral da Presidência da República; ao setor privado cumpre a elaboração de Planos de Gerenciamento de Resíduos Sólidos.

Um dos maiores propósitos da PNRS é a inclusão social e produtiva do catador na cadeia de reciclagem por meio do desenvolvimento de tecnologias sociais. A inclusão é em torno dos sujeitos pertencentes a grupos minoritários em termos de participação ativa nos processos sociais, bem como no pleno gozo dos direitos de cidadania (PINSK; ELUF, 2000). O desenvolvimento local implica esforços articu- lados de atores estatais e da sociedade, dispostos a levar adiante projetos que surjam de negociações de interesses, inclusive divergentes e em conflito (TENORIO et al., 2013). Assim sendo, o desenvolvimento se torna multidimensional conforme afirma Sachs (2004), na medida em que abrange todo o espectro de necessidades materiais e não-materiais do ser humano. O conceito de desenvolvimento local tem como característica fundamental a transdisciplinaridade, em que a sustentabilidade econômica, a qualidade de vida, a inclusão social, o empreendedorismo, o empoderamento, a cidadania, a cooperação e a governança são partes integrantes deste todo (KRONEMBERG, 2011).

Já tecnologia social representa produtos, técnicas e/ou metodologias reaplicáveis, desenvolvidas na interação com a comunidade e que representam efetivas soluções de transformação social (DAGNINO, 2011). Trata-se de uma proposta participativa de construção do conhecimento, de fazer ciência e tecnologia, para o desenvolvimento e realização do ser humano e de seus interesses coletivos e, por isso, é uma forma de reduzir as desigualdades sociais e promover a inclusão social como em Dagnino (2010a; 2010b) e Thomas (2009).

Para responder à questão geral desta pesquisa sobre quais as limitações e potencialidades da cooperativa CATAMARE em tecnologias sociais para o desenvolvimento local em ações sustentáveis, foi desenvolvido um estudo de caso qualitativo, como tratado em Yin (2005), para quem o estudo de caso reflete uma pesquisa empírica para investigar um fenômeno contemporâneo em sua conjuntura natural. A relevância do estudo está vinculada a dois campos: i) alternativas de produção ligadas ao desenvolvimento metodológico da tecnologia social e ii) manifestações produtivas que almejam o desenvolvimento local por meio de ações sustentáveis.

Este artigo, além da Introdução, está organizado em seis seções. Seção 2 - Base 
Teórica, Seção 3 - Método e Design de Pesquisa, Seção 4 - Análise e Resultados, Seção 5-Limites e potencialidades da Cooperativa CATAMARE e Seção 6 Conclusão.

\section{BASE TEÓRICA}

\subsection{Tecnologia, inclusão e desenvolvi- mento local}

As tecnologias condicionam as estruturas de distribuição de renda e de consumo, facilitam ou dificultam o acesso a bens, serviços e conhecimentos, ou seja, geram condições para a inclusão ou exclusão social (THOMAS, 2009). De modo geral, sob a lógica do capital, o padrão tecnológico dominante é denominado de tecnologia convencional e pode ser definida a partir de um conjunto de características relativas aos seus efeitos sobre o trabalho e ao meio ambiente, à sua grande escala e ritmo de produção, aos insumos utilizados e ao tipo de controle exercido sobre os trabalhadores (DAGNINO, 2004; BRANDÃO, 2001).

A concepção de Tecnologia Social (TS) apresenta um enfoque inclusivo e abrangente (DAGNINO, 2004). A tecnologia social é uma proposta participativa de construção do conhecimento, de fazer ciência e tecnologia para o desenvolvimento e realização do ser humano e de seus interesses coletivos e, por isso, é uma forma de reduzir as desigualdades sociais. Sob esta perspectiva, é possível afirmar que esse tipo de tecnologia é expressa pela intervenção social, que é inclusiva em todos os seus momentos, desenvolvida e difundida de acordo com as possibilidades e as limitações de cada comunidade ou local.

Para Dagnino (2010b) a compreensão de que o problema da exclusão social e a tecnologia estão intimamente relacionados e de que a segunda pode desempenhar um papel importante na redução das desigualdades sociais e numa transformação do padrão tecnológico do- minante está no cerne do conceito de TS. Há uma série de evidências que permitem perceber um esforço de sistematização no sentido de estabelecer o que de fato é essencial para o sucesso de experiências de desenvolvimento de tecnologias sociais capazes de promover a inclusão social. A construção coletiva de novas soluções se dá nos regimes sociotécnicos existentes a saber: cultura dominante, estrutura e práticas incorporadas em infraestruturas físicas e imateriais (caminhos, rotinas, relações de poder e regulações), como em Loorbach (2007). Nesse caso, a inclusão é em torno dos sujeitos pertencentes a grupos minoritários em termos de participação ativa nos processos sociais, bem como no pleno gozo dos direitos de cidadania (PINSK; ELUF, 2000).

Orientadas pelos critérios de inclusão social, as tecnologias sociais permitem a construção de sistemas socioeconômicos mais justos em termos de distribuição de renda e mais participativa em termos de tomada de decisão coletiva (THOMAS, 2009). Por outro lado, a inclusão pressupõe sistemas diferenciados de arranjos organizacionais para que haja a oportunidade para os indivíduos. Havia desde 1970, um tipo específico de conhecimento que tornou possível a reciclagem em grande escala de papel, papelão e de resíduos plásticos (FORLIN; FARIA, 2002). Mesmo no caso do alumínio, alguns recursos técnicos e tecnológicos para a transformação desse tipo de resíduo em matéria-prima já existiam. Assim, ao contrário do que se pode cogitar, foi uma força de trabalho numerosa de catadores que tornou tais tecnologias economicamente viáveis para serem empregadas no país, possibilitando a expansão exponencial do negócio da reciclagem no Brasil.

\subsection{Cooperação, gestão social e governança}

Para Asttley e Fombrun (1983) e Astley (1984) a ideia da colaboração é 
uma alternativa para negócios. Os autores transformaram os conceitos de competição em cooperação, destacando o conceito de estratégias coletivas como "atividade de formação conjunta de políticas e implementação de ações pelos membros de coletividade interorganizacionais", o que vem ao encontro da gestão social. Cabe lembrar que a tomada de decisão sobre estratégias é sempre coletiva, pode ser denominada de heterárquica e baseada no interesse comum, ou seja, o grupo busca o que interessa ao coletivo (e assim se chega ao interesse individual) por meio do diálogo intersubjetivo (TENORIO et al., 2013).Ainda de acordo com os autores, outra característica da gestão social é a transparência ou a coletivização das informações obtidas no processo de gestão. Trata-se de uma das condições do processo, e sempre está presente a busca pela intersubjetividade e dialogicidade. Para os autores, sem essas condições, a tomada de decisão coletiva não poderia ser considerada como tal, e a ação comunicativa não se faria presente neste tipo de gestão. Dessa forma, a tomada de decisão na gestão social traz uma perspectiva de interdependência entre os atores no sentido da discussão proposta por Cançado (2011), ou seja, interdependência baseada na solidariedade (responsabilidade recíproca entre atores), tendo como horizonte a sustentabilidade, não apenas no sentido ambiental, mas no sentido amplo do termo (TENÓRIO et al., 2013).

Complementar à cooperação e à gestão social, outro importante enfoque é a governança participativa. Em Gaudin (2007), governança é fruto de um contrato negociado entre partes e que a priori deve-se considerar como um processo limitado, dadas as assimetrias dos atores envolvidos e suas capacitações. Para Le Galés (2006, p. 25), "governança é um processo de coordenações de atores, de grupos sociais, de instituições ou de redes empresariais para alcançar objetivos discutidos e definidos coletivamente" A instalação de uma go- vernança deve ser oriunda de um amplo processo de negociação e discussão a fim de que desde então se institucionalize o processo de negociação entre os participantes do grupo (TENÓRIO et al., 2013).

\section{METODO E DESIGN DA PESQUISA}

Esta seção apresenta a metodologia e os procedimentos adotados para a realização desta pesquisa a fim de responder: Quais as limitações e potencialidades da cooperativa CATAMARE em tecnologias sociais para o desenvolvimento local em ações sustentáveis?

O procedimento técnico utilizado, em um primeiro momento, foi a pesquisa bibliográfica, que possibilitou a elaboração do referencial teórico e abordou principalmente artigos e documentos oficiais. Após essa etapa foi realizado o estudo de caso na cooperativa CATAMARE. De forma sucinta, Yin (2005) define o estudo de caso como uma pesquisa empírica que busca investigar um fenômeno contemporâneo em sua conjuntura natural, "em situações em que as fronteiras entre o contexto e o fenômeno não são claramente evidentes", o que compele, para o presente trabalho, a utilização de múltiplas fontes de evidência.

Foram realizadas visitas periódicas à cooperativa para que se pudesse realizar a observação participante. Essa ação permitiu a verificação in loco do modus operandi dos cooperados no que tange ao funcionamento do processo de operação da cooperativa e sua governança.

Uma série de entrevistas em profundidade foram realizadas no decorrer da investigação. Foram entrevistados tanto os cooperados que ocupavam funções estratégicas como o presidente, o conselho fiscal, a tesoureira e os participantes da comissão de comercialização. Também foi realizada nesse período a aplicação de um questionário para todos os cooperados que se dispuseram a participar da pesquisa e, de um universo de 39 cooperados, 26 responderam ao questionário. Nas entrevistas realizadas, grande parte deles 
acredita que uma saída para os problemas da cooperativa é diminuir a distância entre o trabalho que realizam e onde são feitas pesquisas e projetos que levam em consideração as demandas da categoria. Contudo os obstáculos que se colocam no âmbito das atividades de pesquisa são igualmente significativos

\section{ANÁLISE E RESULTADOS}

A cooperativa CATAMARE conta com 35 cooperados que estão organizados por meio da estrutura hierárquica que pode ser observada na Figura 1.

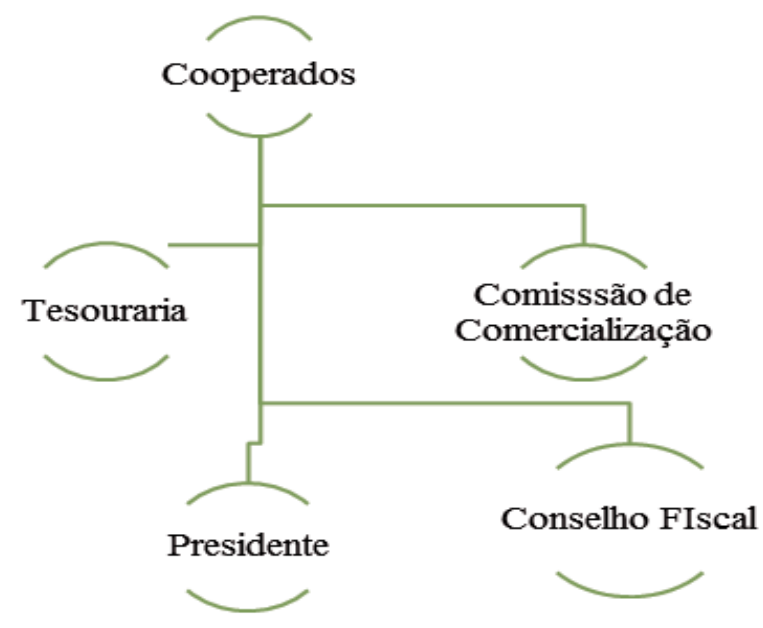

Figura 1 - Estrutura Hierárquica da CATAMARE

Fonte: Autoria própria.

Embora a Figura 1 represente uma estrutura hierárquica verticalizada, de acordo com os cooperados o grupo tem um maior poder de decisão que o presidente e ocupa uma das funções estratégicas do empreendimento. Os 26 cooperados responderam que todas as decisões da cooperativa são tomadas por votação em assembleia, após discussão prévia. Nessas reuniões, inclusive, é que se vota nos cooperados que se elegem para ocupar as funções estratégicas da organização. É vedada a participação de qualquer pessoa que não seja cooperada nas assembleias do empreendimento.

O presidente é quem responde juridicamente por todas as atividades da cooperativa. É, em suma, quem representa a cooperativa nos encontros, reuniões e atividades oficiais e que procura soluções para as demandas dos cooperados fora dos limites da organização.

A comissão de comercialização é um núcleo formado por cooperados da CATAMARE, mas que também faz parte de um grupo da Cataparaná, que tem o intuito de estudar as melhores opções de comercialização conjunta do material dos catadores via rede para a indústria. A comissão tem a responsabilidade de participar das reuniões com outros associados e cooperados que fazem parte da Cataparaná, o que ocorre uma vez por mês. Todo o planejamento do empreendimento é feito em assembleia por todos os cooperados. Cada um pode identificar, antes da reunião, as demandas que precisam ser discutidas e votadas. Nesse sentido, as assembleias são a principal ferramenta de envolvimento dos cooperados com as demandas coletivas do empreendimento. Ficou estipulado entre os cooperados que cada catador deve contribuir com $20 \%$ de seu rendimento mensal obtido - a renda de cada catador depende invariavelmente do seu potencial de produção. Com esse valor, o empreendimento paga luz, água, internet, telefone e manutenção das máquinas utilizadas por todos nos barracões da cooperativa. Alguns catadores não concordam com essa divisão. Para eles, isso enfraquece o cooperativismo entre os catadores e não leva em consideração princípios da economia solidária. Atualmente a cooperativa Catamare sedia dois galpões de triagem, em ambos os barracões, as principais etapas de processamento de resíduos da CATAMARE são: i) o recebimento do material; ii) o descarregamento dos caminhões; iii) a triagem dos materiais, iv) a prensagem; v) o enfardamento; e vi) o armazenamento dos recicláveis. A partir das observações in loco, foi elaborado um fluxograma do processo produtivo da cooperativa como pode ser observado na Figura 2. 


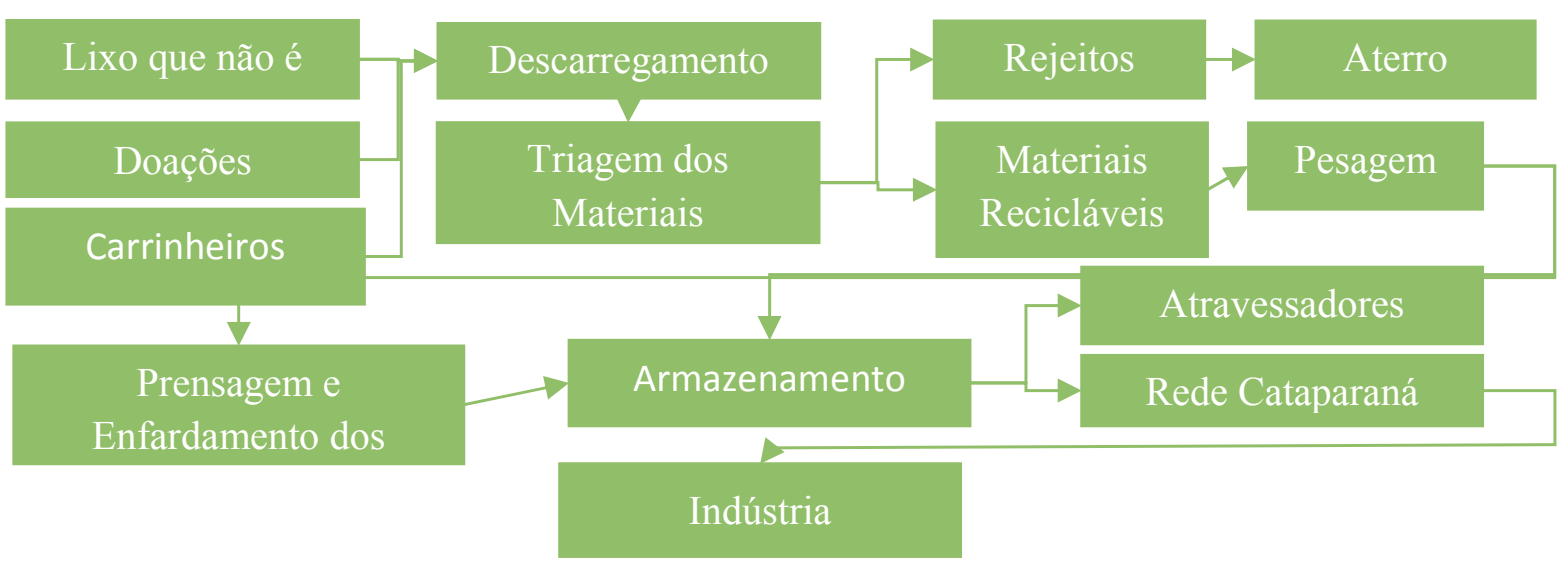

Figura 2 - Fluxograma do processo produtivo da cooperativa CATAMARE Fonte: Autoria própria.

Como representado na Figura 2, diariamente a cooperativa recebe material do projeto "Lixo que não é Lixo", da coleta feita nas ruas pelos seis carrinheiros da cooperativa e doações de empresas e órgãos públicos. A CATAMARE possui um caminhão de grande porte, um caminhão pequeno (adquirido neste ano através de um projeto da Funasa) e uma Kombi para fazer a coleta das doações. Porém, devido à deterioração da Kombi, o uso dos caminhões foi intensificado, e a cooperativa já não consegue mais recolher todos os recicláveis nas organizações doadoras, e estas, por sua vez, têm dificuldade (ou, na voz dos catadores, dificultam) para fazer a entrega dos materiais nos barracões. Quando questionados sobre o compartilhamento de técnicas no barracão, 18 cooperados responderam que compartilham saberes com seus colegas. Os catadores indicaram que a maioria das conversas é sobre a qualidade e os tipos de materiais que eles manejam. Outros cooperados disseram que eles buscam falar sobre os direitos do catador com os outros catadores. Um cooperado afirmou que divide com os outros cooperados que ainda fazem catação na rua os saberes sobre os melhores lugares para se conseguir material. Dois catadores afirmaram que gostam de conversar sobre novidades que eles ouvem de cooperados de outros barracões ou sobre as discussões do Fórum Lixo e Cidadania.
Quando perguntados se a cooperativa busca formas para promover melhorias dos artefatos utilizados no manejo dos materiais, 23 catadores responderam que a cooperativa procura aperfeiçoar os objetos e maquinarias necessárias para a atividade. Para 14 cooperados, isso acontece principalmente através dos projetos que a cooperativa desenvolve para conseguir subsídios da Fundação Banco do Brasil, da Funasa, do Cataforte e do Ecocidadão. Outros catadores citaram as formações da Cataparaná e os encontros no Fórum Lixo e Cidadania.

Quando interrogados sobre a busca de melhorias nas técnicas e conhecimentos utilizados nos processos, nenhum dos catadores soube relatar exemplos concretos de experiências anteriores.

[...] falta uma diretoria atuante para buscar outros conhecimentos e alternativas para a cooperativa. O problema é que todo mundo está preocupado com a sua própria mesa na CATAMARE. Não foi sempre assim, mas hoje em dia é cada um por si.

Embora os catadores pareçam interessados em aprimorar os processos realizados na cooperativa, isso está dentro de uma lógica essencialmente instrumentalizada. Para um dos cooperados, a falta de interesse de buscar outras formas para resolver os problemas do empreendimento 
é um dos fatores mais preocupantes para a sobrevivência da unidade produtiva.

De fato, através da observação, foi possível constatar o esforço dos catadores bem como as longas e exaustivas jornadas de trabalho que enfrentam. Ainda, por meio das entrevistas realizadas foi possível identificar as principais organizações com que a CATAMARE mantém relações. Foram listadas pelos catadores entrevistados, 43 organizações que, na visão deles, condicionam a sobrevivência da cooperativa. Há 27 órgãos públicos fazendo parte da rede. Destes, 18 são órgãos doadores. As outras nove organizações desenvolveram projetos que beneficiaram a cooperativa ou são responsáveis pelas políticas públicas que têm ligação direta com a atividade da catação. Há apenas quatro empresas privadas relevantes na rede da cooperativa - essas organizações doam material para a CATAMARE. Foram citadas somente três organizações geridas por catadores - entre elas estão a Cataparaná, o Movimento Nacional e uma cooperativa. Outra organização sem fins lucrativos citada pela maioria dos catadores é o Instituto Lixo e Cidadania. Ao observar a classificação dos principais atores percebe-se a importância das organizações do terceiro setor, da rede autogerida pelos catadores e das organizações públicas na manutenção estrutural geral da rede da CATAMARE. Entre estas organizações, a que apresenta maior grau de centralidade é a Cataparaná seguida pela Prefeitura. Em terceiro lugar encontra-se o Instituto Lixo e Cidadania. Foi possível perceber que a maioria dos órgãos doadores individualmente parece ter menos influência para o conjunto do que as organizações de apoio da cooperativa. Entre os órgãos doadores mais vezes citados pelos cooperados, há somente a UTFPR e o TRT. Por outro lado, as relações de troca e doação de materiais surgem como um importante elo relacional a ser estudado, representando o fluxo de trocas de materiais entre organizações de catadores e a crescente prática de doação e repasse de materiais recicláveis de grandes organizações públicas e privadas diretamente para organizações de catadores (no caso das organizações públicas, essa prática é compulsória por meio do decreto n. 5940 de 2006).

\section{OS LIMITES E AS POTENCIALIDA- DES DA COOPERATIVA CATAMARE}

\subsection{Limites da cooperativa CATAMARE}

A pesquisa identificou que eles realizam seu trabalho em condição permanente de coerção exercida por múltiplos sujeitos sociais. Entre eles se destacam uma parcela do poder público, as comunidades nas quais os barracões estão localizados e dos próprios empresários das empresas que trabalham com reciclagem ou que deveriam doar o material para a cooperativa. A flutuação do preço do material é outro fator que compromete não só a CATAMARE, mas todas as cooperativas de catadores. De acordo com os catadores, há um declínio sazonal nos valores do reciclável e esta queda tem relação com o mercado internacional, com as crises econômicas e política cambial, que afetam diretamente o preço dos materiais. A qualidade oligopólica da indústria da reciclagem, segundo os catadores, também afeta os preços pagos pelos materiais, fato que restringe quase que inteiramente a margem de comercialização do que produzem e, consequentemente, a negociação do preço de seu trabalho.

Não é raro ver claramente nos projetos dos quais a CATAMARE participou - seja de pesquisas de universidades, seja aqueles promovidos pelo poder público - apresentação de pacotes tecnológicos, quando tanto os pesquisadores como o poder público deveriam na verdade se preocupar com o efetivo envolvimento dos catadores na construção das soluções para seus problemas. No caso desses possíveis projetos, há que se destacar o problema da não funcionalidade de parte dos conhecimentos que os estruturam: há uma 
visão bastante instrumentalizada e, muitas vezes, sua concepção não permite o total envolvimento da categoria na construção dos projetos, o que dificulta a criação de estratégias de solução de problemas a médio e longo prazo. Como consequência, há a persistência em soluções que não contemplam de fato a realidade desses trabalhadores, e muitos temas socialmente relevantes para eles não se convertem em objetos de análise e escopo de trabalho.

A relação da cooperativa com o poder público é bastante contraditória: Se, por um lado, existem projetos federais, municipais e estaduais que permitem o financiamento de equipamentos e artefatos para melhorar a condição de trabalho dos catadores, por outro lado, isso acontece dentro de uma racionalidade totalmente determinista: de acordo com os relatos dos catadores há diversas restrições sobre os tipos de materiais que podem ser obtidos com o repasse da União. Ou seja, ao mesmo tempo em que existe uma potencialidade na relação da cooperativa com o poder público, essa mesma relação impõe diversos limites para que se construa a inclusão social dos catadores e o desenvolvimento de tecnologias alternativas que correspondam às demandas dos cooperados.

Ao mesmo tempo em que se criam políticas públicas federais e estaduais que consideram a inclusão social e se desenvolvem projetos financiados por instituições públicas beneficiadoras das cooperativas e associações dos catadores, os municípios e o governo estadual não cumprem grande parte dessas leis: não há, por exemplo, o investimento em projetos voltados para o desenvolvimento e reaplicação de processos, métodos e artefatos que considerem as necessidades da atividade da catação. Embora existam encontros de formação sobre autogestão -organizados pelo Instituto Lixo e Cidadania, pela Cataparaná e pelo MNCR -, sustentabilidade e administração do barracão, que acontecem espaçadamente nos encontros nacionais e regionais dos catadores e nos encontros do Cataforte, o único projeto relatado pelos cooperados em que eles participaram de forma precária no desenvolvimento foram os carrinhos elétricos projetados pela Itaipu.

A falta de pesquisas e de projetos que visem melhorar as condições de trabalho prejudica que se realizem ações qualificadas pelo montante baixo de aportes financeiros capazes de viabilizar economicamente o empreendimento cooperativo. Nesse sentido, um dos aspectos mais preocupantes na unidade produtiva diz respeito à união entre os catadores e a organização dos barracões. A divisão dos catadores nos barracões promoveu a diferença da organização do trabalho: alguns grupos de catadores separam igualmente todos os recicláveis que chegam à cooperativa, outros grupos dividem o material por órgão doador. Isso pode ser um aspecto limitante já que incentiva a competição entre os trabalhadores e desestabiliza os valores solidários necessários para o crescimento do empreendimento.

Embora os cooperados se preocupem em consolidar a autogestão no empreendimento, foi possível perceber que ela não acontece em prol do desenvolvimento da cooperativa. A falta de tempo e a necessidade que os catadores têm para atingir uma renda digna através de longas jornadas de trabalho se apresentam como entraves para a união dos catadores. Cada um trabalha muito, porém, sem a organização coletiva, política e econômica da cooperativa é muito difícil almejar ganhos, inclusive financeiros, para o catador. Foi possível perceber também que há certos limites na ação da cooperativa sobre outras esferas da vida dos cooperados. Há pouca articulação em relação a outras demandas sociais que foram relatadas pelos catadores.

\subsection{Potencialidades da cooperativa CATAMARE}

Os catadores de material reciclável que fazem da coleta e da triagem o 
seu meio de subsistência, possuem um importante papel socioambiental já que cooperam para minimizar os impactos ambientais ao recolherem os recicláveis da cidade e geram riqueza ao realizarem a triagem e o beneficiamento dos resíduos, sendo possível assim destinar novamente os materiais à indústria, e não aos aterros sanitários.

Por outro lado, há um potencial latente na CATAMARE: a maioria dos cooperados entende a necessidade de explorar outras ferramentas, artefatos e métodos no processo produtivo da organização, embora o empreendimento não participe e não desenvolva atualmente nenhum projeto. Esse grupo de catadores vê, de forma positiva, as possíveis parcerias que podem constituir com as universidades da região e com o próprio poder público. Nesse sentido, outro fator importante diz respeito à consciência política e social que os catadores têm, mas que encontra limites na ação do poder público e na percepção das instituições de pesquisa.

Quando questionados sobre o significado que atribuíam à inclusão social, metade dos catadores apresentou uma visão bastante abrangente do conceito. Em consonância à definição apresentada no desenvolvimento teórico do trabalho, vários catadores falaram sobre a conquista de direitos. Entre os mais citados estavam: o direito à educação, à saúde, à moradia, ao trabalho e ao espaço público. Muito catadores falaram que questões raciais e orientação sexual devem ser respeitadas para que seja possível ser incluído socialmente. Para os catadores que responderam à questão, uma sociedade sem preconceitos e discriminações é uma sociedade que inclui. Outros também imputaram ao significado do termo a participação nas decisões que afetam suas vidas. Muitos catadores falaram sobre reconhecimento, visibilidade e valorização, e alguns ressaltaram a necessidade de reconhecimento pela atividade de trabalho que desempenham.
É possível afirmar, nesse sentido, uma clareza na postulação das necessidades sociais que os catadores percebem. No entanto há um ponto positivo, que diz respeito à sensibilização da sociedade sobre a atividade da catação, é a consciência que os catadores têm da importância de divulgar o trabalho que realizam, bem como o interesse que os cooperados têm em trazer catadores autônomos e outras pessoas que estão uma situação vulnerável para fazer parte do empreendimento. A cooperativa abriga ex-dependentes químicos e moradores de rua, garantindo-lhes certa remuneração e um trabalho digno. Todavia é possível atribuir a essa dinâmica a alta rotatividade no empreendimento: durante a realização da pesquisa sete catadores se desligaram da cooperativa, e outros 8 foram aceitos.

Os catadores também colaboram para minimizar a extração dos outros recursos naturais. Apesar de realizarem um trabalho extremamente importante tanto para a cidade quanto para o setor produtivo já que as empresas de reciclagem lucram em cima do valor do trabalho dos catadores, estes não têm sua importância reconhecida social e economicamente e são, constantemente, discriminados e marginalizados. Sendo assim, a organização política dos catadores se apresenta com uma potencialidade de empoderamento da classe. Dentre as principais formas de organização, encontram-se o Movimento Nacional e a rede Cataparaná. O Movimento Nacional dos Catadores de Recicláveis busca garantir a independência de classe em relação aos partidos políticos, governos e empresários, ao mesmo tempo em que luta pela gestão integrada dos resíduos sólidos com participação ativa dos catadores organizados. O movimento acredita também que é um ponto estratégico desenvolver tecnologias viáveis que garantam o controle da cadeia produtiva ao catador, bem como firmar com os poderes públicos contratos que garantam o repasse financeiro ao serviço prestado pelo trabalhador, e cobrando das 
empresas privadas o devido pagamento pelo trabalho realizado pelos catadores.

O MNCR foi fundamental para que a inclusão social do catador fosse objeto da Política Nacional de Resíduos Sólidos, todavia a articulação do movimento em suas bases orgânicas ainda é embrionária. Não há um trabalho consistente das cooperativas que o integram. A partir das entrevistas com os cooperados da CATAMARE, não foi possível identificar uma articulação com as outras cooperativas que são base orgânica do movimento ou com o comitê regional. A Cataparaná tem o objetivo de apoiar os grupos organizados em rede para comercializar, beneficiar e estocar conjuntamente os materiais dos empreendimentos solidários. Através dessa estratégia que, de acordo com catadores, foi possível de fato melhorar a renda com a comercialização dos materiais. A função da rede é de atender não só os grupos que já estão mais fortalecidos, como aqueles que estão desamparados pelos poderes públicos municipais.

Em síntese, pode-se inferir que o catador de materiais recicláveis é incluído ao ter um trabalho, mas excluído pelo tipo de trabalho que realiza, pela classe trabalhadora que representa a que se soma a discriminação de gênero e raça já que a maioria dos catadores são mulheres negras e mães solteiras. Apesar de todos os ganhos políticos para a categoria, as cooperativas funcionam como uma forma de trabalho terceirizado das grandes empresas de reciclagem que exploram o trabalho dos cooperados. Independente da organização desse tipo de trabalho, a taxa de lucro produzida deveria competir com preços determinados, por exemplo, pelo mercado mundial responsável pelos derivados de petróleo, pela produção de alumínio e de celulose, ou seja, o trabalho do catador deve estar submetido às variáveis de produção e ao padrão tecnológico imposto pela indústria de recicláveis.

É preciso levar em consideração, mesmo que sinteticamente, a dinâmica e as características da expansão do setor de produção de reciclados no Brasil e sua dependência de uma força de trabalho com qualidades específicas para a coleta e seleção dos materiais recicláveis. É preciso compreender que, embora tenham existido avanços - principalmente no que diz respeito as políticas públicas que reconhecem a importância da atividade da catação -, a indústria da reciclagem ainda depende do trabalho mal pago de uma massa de trabalhadores com baixa escolaridade, sem perspectivas e desunida, que se vê dependente de instalações e tecnologias dispendiosas e excludentes já que se encontra reprimida pelos interesses do capital envolvido na cadeia da compra, reciclagem e comercialização de todo os resíduos coletados.

Sendo esta a conjuntura, é mais do que admissível declarar que a organização do trabalho, a jornada e a renda dos catadores é compulsoriamente articulada pelo preço dos recicláveis. Atualmente a Cataparaná comercializa diversos tipos de recicláveis com empresas de São Paulo e, por outro lado, segundo os catadores, muitos materiais do interior paulista chegam até a rede para serem comercializados para que essas cooperativas possam vender seus fardos por preços melhores. Esse processo de depreciação dos preços pagos pelo material triado é percebido por todos catadores que participaram da entrevista e, segundo eles, quase não há concorrência de preços entre os compradores de recicláveis.

Atualmente, o problema está em reconhecer o direito do catador às condições dignas de trabalho e de vida para além da perspectiva estrita da sobrevivência. A ausência de ações dirigidas que contemplem não só os problemas vividos nos barracões de triagem, mas também o acesso à educação, à moradia, à saúde, ao transporte público dos catadores, bem como a violência doméstica sofrida por diversas catadoras, que é um outro limite que precisa urgentemente ser transposto. Os problemas da cooperativa desafiam a usual distinção entre técnico e social: As soluções empregadas para combatê-los devem ser entendidas como condiciona- 
das por processos sociotécnicos complexos. Nesse sentido, para que a exclusão social dos catadores não se dê via inclusão parcial pelo trabalho, é preciso que o poder público e as instituições de apoio considerem as especificidades das demandas dos catadores, que invistam em pesquisa e desenvolvimento para soluções adequadas à rota tecnológica da reciclagem popular e articulem diferentes políticas.

Para os cooperados é possível construir uma sociedade menos desigual se houver incentivo para o desenvolvimento de empreendimentos solidários. No limite isso acontece por meio de práticas que combatem a competição e o individualismo, da autogestão do trabalho, e o apoio mútuo entre os catadores e outros trabalhadores. Como classe trabalhadora, há a intenção de que os catadores avancem no controle da cadeia produtiva de reciclagem para garantir que o serviço realizado sirva ao fortalecimento socioeconômico da categoria como um todo.

\section{CONCLUSÃO}

As questões problematizadas na pesquisa indicaram que a organização do trabalho dos catadores se realiza a partir dos interesses do capital envolvido na cadeia de compra, reciclagem e comercialização. As evidências sugerem que eles realizam seu trabalho em condição permanente de coerção exercida por múltiplos sujeitos sociais, além da própria concorrência velada existente entre os próprios catadores.

Como resultado, as evidências sugerem que a organização da cooperativa permitiu acesso a informações sobre legislação da PNRS. Mas apontou para a necessidade de fortalecimento de relações com instituições de educação e do poder público, para que a despeito da baixa qualificação dos cooperados, projetos e conhecimento pudessem ser desenvolvidos em prol de tecnologias sociais, visto que se observou ausência de inovações tecnológicas e produção de artefatos alternati- vos a partir de materiais recicláveis. Isso fragiliza a cooperativa para a articulação entre pares, notadamente a integração na rede de relacionamentos da Cataparaná, que apoia a comercialização de material produzido para a indústria.

Embora os catadores organizados em cooperativas consigam conquistar alguns benefícios econômicos e sociais que contribuem para a sua qualidade de vida, na medida em que estes se envolvem nos movimentos sociais que se preocupam com a sua atividade, começam a perceber o papel que desempenham na preservação do meio ambiente e descobrem-se como cidadãos por direito. A organização política dos catadores e a consciência de classe dos trabalhadores aliados às relações que a cooperativa estabeleceu com o poder público podem possibilitar o desenvolvimento de tecnologias sociais, embora isso ainda aconteça de forma incipiente. Além disso, programas isolados não alteram totalmente o quadro perverso de exclusão social do catador via inclusão por meio de um trabalho precarizado. Nesse sentido, garantias da universalização e integração de políticas públicas em todas as esferas da administração pública - o que começa a ser edificado por meio do Comitê Interministerial para Inclusão Social e Econômica dos Catadores de Materiais Reutilizáveis e Recicláveis (CIISC).

Pode-se concluir que a adesão à cooperativa melhorou a condição social, econômica e política dos cooperados, mas ainda há limites estruturais da cadeia produtiva da reciclagem que não são contemplados pela Política Nacional de Resíduos Sólidos e que, de certa forma, fragilizam o propósito de desenvolvimento de ações sustentáveis.

Neste contexto, entende-se que o tema é de grande relevância para a pesquisa científica, para os gestores da administração pública e também para as instituições, associações e cooperativas de catadores, que são parceiros no processo de desenvolver a inclusão social. 


\section{REFERÊNCIAS}

ASTLEY, W. G. Toward na appreciation of colletive strategy. Academy of Management Review, v. 9, n. 3, p. 526-535, 1984.

ASTLEY, W. G.; FOMBRUN, C. J. Collective strategy: social ecology of organizational environments. Academy of Management Review, v. 8, n. 4 , p. $576-587,1983$.

BRANDÃO, Flávio. Programa de Apoio às Tecnologias Apropriadas - PTA: avaliação de um programa de desenvolvimento tecnológico induzido pelo CNPq. 2001. Dissertação (Mestrado em Desenvolvimento Sustentável) - Universidade de Brasília (UnB), Brasília, DF.

CANÇADO, Airton Cardoso. Fundamentos teóricos da gestão social. 2011. Tese (Doutorado em Administração) - Universidade Federal de Lavras, Lavras, MG, 2011.

DAGNINO, Renato. Tecnologia social: base conceitual. Ciência \& Tecnologia Social, v. 1, n. 1, jul. 2011. Disponível em: <http:// periódicos. Unb.br/index.php/cts/article/ view/3840/4328>. Acesso em: 19 mar. 2016.

A tecnologia social e seus desafios. 2004. Disponível em: <http://www.ige. unicamp.br/site/publicacoes/138/A\%20 tecnologia $\% 20$ social $\% 20$ e $\% 20$ seus $\% 20$ desafios.pdf>. Acesso em: 21 mar. 2013.

Gestão social e gestão pública: interfaces, delimitações e uma proposta. Revista Brasileira de Administração Politica, Bahia, v. 3, n. 02, p. 21-32, 2010a.

DAGNINO, Renato (Org.). Tecnologia social: ferramenta para construir outra sociedade. Campinas, SP: Unicamp, 2010b.
FORLIN, Flávio; FARIA, José de Assis. Reciclagem de embalagens plásticas. Polímeros: Ciência e Tecnologia, v. 12, n. 1, p. 1-10, 2002. Disponível em: <http://www.scielo.br/pdf/ po/v12n1/9876>. Acesso em: 10 dez. 2014.

GAUDIN, J. P. Gouverner par contrat. 2. ed Paris: Presses de Science Po, 2007.

KRONEMBERGER, Denise. Desenvolvimento local sustentável: uma abordagem prática. São Paulo: SENAC, 2011.

LES GALÉS, P. (Dossier rélisé par) Gouvernement et gouvernance des territoires (Problémes Politiques et Sociaux, n. 322). Paris: La Documentation Française, 2006.

LOORBACH, D. Transition management: new mode of governance for sustainable development. Utrecht, Holanda: International Books, 2007.

PINSKY, J.; ELUF, L. N. Brasileiro (a) é assim mesmo: cidadania e preconceito. 6. ed. São Paulo: Contexto, 2000.

SACHS, I. Desenvolvimento: includente, sustentável, sustentado. Rio de Janeiro: Garamond, 2004.

TENORIO, F.; CANÇADO, Airton C.; SAUSEN, Jorge O.; VILLELA, Lamounier E. Gestão social e gestão estratégica: experiências em desenvolvimento territorial. Rio de Janeiro, RJ: Editora FGV, 2013.

THOMAS, Hernán. Tecnologías para la inclusión social y políticas públicas en América Latina. 2009. Disponível em: <http://www.redtisa. org/Hernan-Thomas-Tecnologias-parala-inclusion-social-y-politicas-publicas-enAmerica-Latina.pdf>. Acesso em: 20 set. 2013. YIN, Robert K. Estudo de caso: planejamento e método. 3. ed. Porto Alegre, RS: Bookman, 2005.

\section{Sobre os autores:}

Christian Luiz da Silva: Pós-doutor em Administração pela USP, doutor em Engenharia de Produção, economista, professor do PPGTE, do PGP e do Departamento de Gestão e Economia da Universidade Tecnológica Federal do Paraná (UTFPR). E-mail: christianlsilva76@gmail.com

Camille Rossato Bolson: Administradora e Mestre em Tecnologia pela Universidade Tecnológica Federal do Paraná (UTFPR). E-mail: camille.bolson@gmail.com

Cristina Maria Souto Ferrigoti: Doutora em Administração. Centro Universitário Internacional (UNINTER), Curitiba, PR. E-mail: cmferigoti@uol.com.br 